\title{
The 9th Biennial Meeting of the International Quantum Structures Association
}

\author{
Bart D’Hooghe $\cdot$ Jarosław Pykacz
}

Received: 22 September 2010 / Accepted: 23 September 2010 / Published online: 5 October 2010

(C) Springer Science+Business Media, LLC 2010

The 9th Biennial Meeting of the International Quantum Structures Association (IQSA), hosted by the University of Gdańsk, was held in Sopot, Poland, from 6 to 12 July 2008. Sopot is a renowned spa on the Baltic Sea, located at $15 \mathrm{~km}$ from Gdańsk. On the IQSA website (http://www.vub.ac.be/CLEA/IQSA/conferences.html) the conference is referred to as 'Quantum Structures 2008 Brussels-Gdańsk Meeting'. The reason for this is that it was jointly organised by teams from Gdańsk and Brussels, with members of the Institute of Mathematics and the Institute of Theoretical Physics and Astrophysics of the University of Gdańsk providing the 'hardware' and representatives of the Center Leo Apostel of the Free University of Brussels ensuring the 'software' of the conference. Although originally the 9th Biennial IQSA Meeting was to be held in Brussels, it was mainly because of the high costs involved that it was rescheduled to take place in Poland, but maintaining the Brussels team's significant organisational role. Until the current divide between low-cost and highcost countries within the European Union is bridged, this is something that organisers of future conferences may do well to take into account in choosing their venue.

The Meeting was organised as a low-budget conference to facilitate the participation of IQSA members from emerging countries. The great success of this formula was largely thanks to the University of Gdańsk, which allowed participants to use its facilities at no cost and made its student dormitories available at extremely modest prices. The number of active participants in the Meeting was close to 90 , whilst the overall number of people attending was over one hundred. On Wednesday 9 July 2008, they first enjoyed a sightseeing tour of Gdańsk's historic centre and then set off for a Medieval Evening at a restored medieval settlement in the Sopot area. Here, they were treated to a formidable piece of roasted wild

B. D’Hooghe ( $\varangle)$

Center Leo Apostel (Clea-FUND) and Department of Mathematics, Vrije Universiteit Brussel (VUB),

Brussel, Belgium

e-mail: bdhooghe@vub.ac.be

J. Pykacz

Institute of Mathematics, University of Gdańsk, Gdańsk, Poland

e-mail: pykacz@math.univ.gda.pl 
boar and introduced to the world of medieval martial arts through a display of medieval knights - who were actually scientific staff members from the University of Gdańsk. After this, everybody could have a go at the arts of archery and spear throwing. We wish to add that no animals (except the wild boar) or people were harmed during this evening of medieval martial arts.

In addition to being a sociable event, the Meeting was a great success scientifically, providing its participants an excellent opportunity to present and share their findings and ideas, and to establish new and re-inforce existing friendships, all of which is reflected in the present volume. Importantly, all papers submitted were subject to a strict refereeing procedure, so that this publication does not include all papers that were originally submitted for that purpose. However, due to an unexplicable course of events, rather than being included here, the following three papers were published in regular IJTP issues:

1. Anatolij Dvurečenskij and Marek Hyčko: Bounded Boolean powers and free product of GMV-algebras. Int. J. Theor. Phys. 49, 1595-1611 (2010). doi:10.1007/s10773-0100342-1

2. Franklin E. Schroeck, Jr.: The Poincaré group in demisemidirect product with a nonassociative algebra with representations that include particles and quarks-II. Int. J. Theor. Phys. 48, 3586-3595 (2009). doi:10.1007/s10773-009-0165-0

3. Ekaterina Turilova: Measures on classes of subspaces affiliated with a von Neumann algebra. Int. J. Theor. Phys. 48, 3083-3091 (2009). doi:10.1007/s10773-009-0102-2

Be that as it may, this volume provides a clear overview of the talks, discussions and at times heated arguments that took place at Sopot in July 2008. 